\title{
Managerial perspectives on employee engagement
}

\author{
Niki Romanou ${ }^{1 *}$, Emma Soane ${ }^{1}$, Katie Truss ${ }^{2}$, Kerstin Alfes ${ }^{2}$, Chris Rees ${ }^{3}$, Mark Gatenby ${ }^{4}$, Nick E Degleris ${ }^{5}$, \\ Eleftheria Mantelou ${ }^{5}$, Andreas Solias ${ }^{5}$, Manto Karamberi $^{5}$ \\ From $1^{\text {st }}$ International Congress on Neurobiology and Clinical Psychopharmacology and European \\ Psychiatric Association Conference on Treatment Guidance \\ Thessaloniki, Greece. 19-22 November 2009
}

\section{Background}

Senior management and leadership are believed to be responsible for the employment of such initiatives and their own level of engagement appears to have a strong impact on the levels of employees' engagement, theory suggests. This qualitative research explores the perceived levels, drivers and benefits, as well as the levels of managerial engagement at Organisation A, a leading support services company in the UK. This working paper means to contribute to previous studies of engagement conducted by the Kingston Business School Employee Engagement Consortium.

\section{Materials and methods}

In total, 25 managers were interviewed and semistructured interviews took place in February and March 2009 at the company's headquarters. In this working paper, the research model consists of five thematic principles: drivers and counter-divers of engagement, methods of engagement, (perceived) levels of employee engagement, (perceived) benefits of employee engagement, and managers' levels of engagement. These five core principles entail all the information needed to test the engagement process in the present organisation. In order to assess the sustainability of the research model, the method of template analysis was chosen.

\section{Results}

Not surprisingly, the perceived levels of engagement are moderately high and managers seem to be engaged in their organisation driven by the challenging nature of the work, the recognition they receive and the feelings of

${ }^{1}$ Department of Management, London School of Economics and Political Science, UK accomplishment following a successful task. In line with these, what drives employee engagement is only slightly different: employees seem to be driven not only by the nature of their work but also by the career opportunities available at Organisation A and the collaborative and team-based organisational culture. In terms of benefits, employee engagement seems to lead to heightened organisational performance, improved customer satisfaction and low levels of absenteeism and turnover.

\section{Conclusions}

Managers were completely capable of identifying problematic areas in the engagement process and given the necessary resources might be in position to work on improving some critical elements of it.

\section{Author details}

${ }^{1}$ Department of Management, London School of Economics and Political Science, UK. ${ }^{2}$ Kingston Business School, Kingston University, UK. ${ }^{3}$ School of Management, Royal Holloway, UK. ${ }^{4}$ School of Management, University of Surrey, UK. ${ }^{5}$ Psychotherapeutic Center of Piraeus, Greece.

Published: 22 April 2010

References

1. Bakker AB, Schaufeli WB: 'Positive organizational behavior: Engaged employees in flourishing organizations'. Journal of Organizational Behavior 2008, 29:147-154.

2. Gatenby M, Rees C, Soane E, Truss K: Truss: Employee engagement in context. London: CIPD 2008.

3. King N: 'Using templates in the thematic analysis of text'. Essential Guide to Qualitative Methods in Organizational Research London: SageCassell C, Symon G 2004.

4. Macey WH, Schneider B: 'The meaning of employee engagement'. Industrial and Organizational Psychology: Perspectives on Science and Practice 2008, 1:3-30

doi:10.1186/1744-859X-9-S1-S172

Cite this article as: Romanou et al:: Managerial perspectives on employee engagement. Annals of General Psychiatry 2010 9(Suppl 1):S172. 